Illinois State University

ISU ReD: Research and eData

Theses and Dissertations

2-21-2015

\title{
A Qualitative Assessment Of Eating Behaviors In Adults With
} Autism

Samantha Barbier

Illinois State University, sjbarbi@ilstu.edu

Follow this and additional works at: https://ir.library.illinoisstate.edu/etd

Part of the Human and Clinical Nutrition Commons

\section{Recommended Citation}

Barbier, Samantha, "A Qualitative Assessment Of Eating Behaviors In Adults With Autism" (2015). Theses and Dissertations. 317.

https://ir.library.illinoisstate.edu/etd/317

This Thesis is brought to you for free and open access by ISU ReD: Research and eData. It has been accepted for inclusion in Theses and Dissertations by an authorized administrator of ISU ReD: Research and eData. For more information, please contact ISUReD@ilstu.edu. 


\title{
A QUALITATIVE ASSESSMENT OF EATING BEHAVIORS \\ IN ADULTS WITH AUTISM
}

\author{
Samantha J. Barbier
}

45 Pages

May 2015

Diagnosis of autism has increased ten-fold in the last 40 years, and adults with autism remain an underrepresented population in research. The purpose of this study was to qualitatively explore the relationship between eating behaviors and autism using a questionnaire and interviews with adults diagnosed with autism spectrum disorder. Four males aged 22-27 were interviewed with their mothers present and completed the Swedish Eating Assessment for Autism Spectrum Disorders (SWEAA). Interviews were analyzed through the process of open coding, and the questionnaires were analyzed to determine consistent findings between the interview and the SWEAA questionnaire. Participants generally recognized hunger and satiety and were consuming a high carbohydrate, high fat diet low in vegetables. Variety in food choices was highly dependent upon encouragement from family members. Participants showed no concern for body image, but parents had taken steps to avoid weight gain as their children aged. Previous nutrition education was not particularly meaningful to participants, however they did understand general healthy eating concepts. 
Parents should encourage variety in the diets of individuals with autism, as negative responses to foods appear to decrease with age. Participants' concern with functionality rather than appearance should be considered in the way weight management is approached by health professionals such as Registered Dietitian Nutritionists. 
A QUALITATIVE ASSESSMENT OF EATING BEHAVIORS

IN ADULTS WITH AUTISM

SAMANTHA J. BARBIER

A Thesis Submitted in Partial Fulfillment of the Requirements for the Degree of

MASTER OF SCIENCE

Department of Family and Consumer Sciences

ILLINOIS STATE UNIVERSITY

2015 
@2015 Samantha J. Barbier 
A QUALITATIVE ASSESSMENT OF EATING BEHAVIORS

IN ADULTS WITH AUTISM

SAMANTHA J. BARBIER

COMMITTEE MEMBERS:

Jennifer Banning, Chair

Julie Schumacher

Bill Anderson 


\section{ACKNOWLEDGMENTS}

I would like to express my sincerest gratitude to my committee chair Dr. Banning and committee members Dr. Schumacher and Dr. Anderson for their expertise and guidance during this process. A special thanks to Dr. Banning for her support, encouragement, and the time she dedicated to helping me develop this thesis. I could not have asked for better mentors throughout this experience.

I would also like to thank my family and friends for their unwavering support and understanding through the ups and downs in this journey. And lastly to Chris, who has been my biggest cheerleader and has motivated and inspired me each and every day: I could not have done this without you. From the bottom of my heart, thank you.

S.J.B. 


\section{CONTENTS}

Page

ACKNOWLEDGMENTS

CONTENTS ii

CHAPTER

I. A QUALITATIVE ASSESSMENT OF EATING BEHAVIORS IN ADULTS WITH AUTISM

$\begin{array}{ll}\text { Introduction } & 1\end{array}$

Study Aims $\quad 4$

Symbolic Interactionism $\quad 5$

$\begin{array}{ll}\text { Methods } & 6\end{array}$

Participants $\quad 6$

Design and Procedure 6

Data Collection and Analysis $\quad 7$

$\begin{array}{ll}\text { Results } & 7\end{array}$

Recognizing Hunger and Satiety 8

Typical Diet and Eating Behaviors 8

Change in Eating Habits and Preferences Over Time $\quad 10$

Attitude Toward Trying New Foods 10

Body Image and Weight 11

Nutrition Knowledge and Physical Activity 12

Discussion 12

Conclusions and Implications $\quad 15$

$\begin{array}{ll}\text { Suggestions for Future Research } & 17\end{array}$

$\begin{array}{ll}\text { References } & 18\end{array}$ 
II. EXTENDED LITERATURE REVIEW 21

Research Directions $\quad 21$

Nutritional Status in Individuals with Autism 22

Food Selectivity in Individuals with Autism 24

Eating Disorders in Individuals with Autism 24

Obesity in Individuals with Autism 25

Recommended Diets: Gluten-Free, Casein-Free Diet 26

Similarities with Other Diseases and Disorders 27

Pica in Autism 28

Aging with Autism Spectrum Disorders 29

The Swedish Eating Assessment for ASD 29

References $\quad 31$

APPENDIX A: Participant Consent Form $\quad 35$

APPENDIX B: Participant Interview Questions 37

APPENDIX C: Swedish Eating Assessment for Autism Spectrum Disorders 39 
CHAPTER I

\title{
A QUALITATIVE ASSESSMENT OF EATING BEHAVIORS
}

\author{
IN ADULTS WITH AUTISM
}

\section{Introduction}

Autism Spectrum Disorder (ASD) is a lifelong disorder. It is characterized by the inability to easily communicate, inappropriate reactions to sensations, and unusual physical coordination, though symptoms vary among individuals (Weintraub, 2013). Autism is a complex disorder of brain development, and according to AutismSpeaks.org, the prevalence has increased ten-fold in the United States over the last 40 years (2014). While some of the increase in prevalence may be explained by improved diagnosis and awareness, it is clear that autism is on the rise, now affecting one in every 68 children. ASD is estimated to affect two million people in the United States and tens of millions worldwide (AutismSpeaks, 2014). Autism occurs in all ethnic groups and is almost five times more common among boys than among girls (Centers for Disease Control \& Prevention, 2015). While the cause is currently unknown, there are speculations that it is a combination of factors, such as genetic predisposition and environmental factors. Prior to the publication of the DSM-5diagnostic manual, ASD was categorized into five different types including autistic disorder, Rett disorder, childhood disintegrative disorder, Asperger 
syndrome, and pervasive developmental disorder-not otherwise specified (PDDNOS) (Weintraub, 2013). Following the DSM-5 diagnostic manual's publication, the diagnosis of autism is no longer categorized, but rather grouped into an umbrella term of autism (American Psychiatric Association, 2013).

Much research has been done regarding nutrition and autism spectrum disorders. However, a majority of the research has focused on children and their nutritional status (Johnson et al., 2008; Reynolds et al., 2012; Xia, Zhou, Sun, Wang, \& Wu, 2010; Zimmer et al., 2012). Individuals with ASD commonly display selective eating behavior and food aversion, which may affect their nutritional status and put them at risk for nutrition related diseases. Children are a heavily studied population because they are in a critical time of development and any nutrient deficiencies can severely impact their growth and development. A metaanalysis determined that children with ASD experienced significantly more feeding problems when compared to their peers (Sharp et al., 2013) and feeding problems, such as refusal to eat or eating a small range of food, and food selectivity, may put them at risk for nutritional deficiencies (Bandini et al., 2010). While it is important to study children, a study involving adults will enrich the current base of knowledge as nutrition is important throughout the lifespan, and proper nutrition is essential in the prevention of chronic diseases.

Autism Spectrum Disorder is currently recognized in the Nutrition Care Manual (NCM), produced by the Academy of Nutrition and Dietetics for dietitians and other health professionals, which provides evidence-and knowledge-based nutrition information for these professionals (Academy of Nutrition and Dietetics, 
2013). The Nutrition Care Manual provides information about common eating behaviors, nutrition interventions, and possible nutrition diagnoses that may be applicable to individuals with ASD. For example, the NCM recognizes the glutenfree casein-free diet (GFCF) as a possible diet intervention for autism. The GFCF diet has been implemented in some individuals, due to the possibility that people with ASD may not be able to absorb and metabolize the peptides in casein and gluten properly (NCM website). Previous research has reported mixed results with this diet and its effectiveness on reducing symptoms still requires further research (Pennesi \& Klein, 2012). A recent review concluded that current evidence is limited and weak, and researchers recommended implementing the GFCF diet only after a diagnosis of an intolerance or allergy to these foods has been made (Mari-Bauset, Zazpe, Mari-Sanchis, Llopis-Gonzalez, \& MoralesSuarez, 2014).

Individuals with autism are at a higher risk for obesity, and some individuals may also be at a higher risk for developing an eating disorder. Because of idiosyncratic eating behaviors that are difficult to regulate, among other factors, such as medications, atypical sleep patterns, and lower levels of physical activity, individuals with ASD are at a high risk for developing obesity (Curtin, Anderson, Must, \& Bandini, 2010; Hinckson, Dickinson, Water, Sands, \& Penman, 2013; Ho, Eaves, \& Peabody, 1997.) This combination of unique factors puts them at a higher risk of developing obesity and possibly other related diseases. The idea that there was a connection between anorexia nervosa (AN) and autism spectrum disorders was initially suggested by Gillberg (1983), and 
has since been explored because of the similar cognitive style and commonalities in behaviors such as repetitive actions, preference for routines, perfectionism, and fixation on details. The link between anorexia and autism, demonstrated by underlying behavioral and cognitive similarities such as rigid behaviors, pre-occupation with the self, attention to detail, and failure to empathize, continues to be an area of interest for researchers (Baron-Cohen et al., 2013).

Another challenging behavior that individuals with autism may display is pica, or craving and eating of non-food substances such as dirt or paint. Pica is of concern due to the possibly severe medical consequences from even just one instance (Lacey, 1990). Fortunately, pica is relatively rare in individuals residing in the community, but is more common in those with intellectual disabilities living in institutional settings (Ashworth, Hirdes, \& Martin, 2009).

There is some overlap in social and behavioral abnormalities between autism spectrum disorders and other diseases such as Alzheimer's, dementia, and schizophrenia. While a direct comparison between eating behaviors in these diseases is not a heavily studied area, there has been some investigation into differences and similarities. Exploring similarities in eating behaviors in other diseases and disorders can provide insight into treatment and care for these individuals.

\section{Study Aims}

Much of the previous research has focused on children, as any nutrient deficiencies may have serious consequences during this critical time of 
development. However, there is a gap in the literature regarding adults living with ASD. During the International Meeting for Autism Research in 2014, researchers acknowledged that adults are vastly underrepresented in autism research. While this is a difficult area to study due to individual variances and conflicting conclusions of previous research, it is important to determine if these behavior patterns continue into adulthood and if so, what the consequences of these behavior patterns may be. This study contributes insight into feeding behaviors and long-term impacts of an adult living with ASD.

The purpose of this study is to qualitatively explore the relationship between eating behaviors and autism using a questionnaire and interviews with adults diagnosed with autism spectrum disorder. The research questions that are being examined were as follows: 1) How have the participants' eating habits changed over their lifetime? 2) What eating patterns are currently present in their diet? 3) How do these eating patterns affect the participants' nutrient intake?

\section{Symbolic Interactionism}

The collected qualitative data of this study were explored within the framework of Symbolic Interactionism (SI). According to Smith \& Hamon (2012) this proposition recognizes that social structure is constantly changing and developing and is not fixed in time. It also offers the idea that individuals develop meaning of objects, gestures, or norms through interaction; the meaning of an object is determined by seeing how others use these objects. Within this premise, the individual and society cannot be separated from each other. Perhaps most important to this study is the fact that SI recognizes that humans 
behave in relation to their environment, and communication, either verbal or nonverbal, causes each person to react and modify behavior. Eating and nutrition is an integral part of every human being's daily life, but these things may mean different things to different people. Symbolic Interactionism was chosen as the framework for this research as it acknowledges meaning derived from social interactions and how these meanings and interactions are interpreted.

\section{Methods}

\section{Participants}

In this study, a purposive sample of adults with autism living in a large Midwest town were interviewed and surveyed. After obtaining approval from the Institutional Review Board of the university, an email was sent to the director of a local support group. In order to maintain confidentiality, the email was then forwarded to individuals who had the option to contact the researcher if they were interested in participating. Individuals were invited to participate if they were over the age of 18 and had a diagnosis of autism. A gift card with the value of $\$ 5$ to Target was offered to everyone who chose to participate in the study. One participant offered to participate when she heard about the study from a source outside of the support group.

\section{Design and Procedure}

Interviews were conducted in the fall of 2014 , with the location of the interview determined by the convenience of the participant. Prior to beginning the interview, informed consent was obtained and the study was explained to participants. Notes were taken during the interviews, and following the interview 
participants completed the Swedish Eating Assessment for Autism spectrum disorders (SWEAA). The interview was conducted prior to the questionnaire to avoid any influence from the questionnaire during the interview.

\section{Data Collection and Analysis}

The interview responses were typed and then analyzed through the process of open and axial coding. Questionnaires were analyzed to determine consistent findings or discrepancies between interview responses and the SWEAA questionnaire. The process of open coding included labeling concepts followed by identifying categories based on their properties and dimensions in the data (Strauss \& Corbin, 1998). For reliability, all interviews were completed and transcribed by the same researcher.

\section{Results}

Four male participants aged 22, 24, 25, and 27 (mean age 24.5) were interviewed and filled out a questionnaire. Each of the participants had their mothers present for both the interview and questionnaire to ensure accuracy of the interview and questionnaire completion. All individuals interviewed completed high school and lived at home with their parents. The subsections that follow represent the themes that emerged from the data analysis; recognizing hunger and satiety, typical diet and eating behaviors, change in eating habits and preferences over time, attitude toward trying new foods, body image and weight, and nutrition knowledge and physical activity. 


\section{Recognizing Hunger and Satiety}

When asked how their bodies felt before and after eating, participants claimed that they could tell when they were hungry or full. While they were not always able to articulate how they communicated what being hungry or full felt like, they acknowledged physical signs of hunger, such as stomach pain and a headache, and satiety as the feeling of no longer being able to eat. One participant described being hungry as "my stomach is bubbling," while another participant stated, "my stomach feels not good, but I don't know how to explain it. I feel like I need to eat." Two of the mothers indicated that the awareness and ability to communicate hunger had improved as their children had aged. One mother explained that they've "come a long way. There's a lot of disconnect from body sensations. He eats when it's time to eat and he's hungry." Another mother said her son "recently, within the last year began telling us he was hungry. He'll say 'I'm not sick of [pizza]' and that means he's hungry." The answers on the SWEAA questionnaire confirmed this, with all participants answering sometimes correct, usually correct, or always correct to the questions "I feel when I am hungry" and "I feel when I am full."

\section{Typical Diet and Eating Behaviors}

Each participant had their own individual food preferences, but many of their preferences overlapped as well. When asked what foods the participants loved to eat, their responses included "whole wheat spaghetti, bread, hot dogs, strawberries, peaches, fish, popcorn, ice cream," "apples and oranges because they're healthy," "pizza, fruits, hot dogs, hamburgers, chicken nuggets, grilled 
cheese, and fries," and "pizza, burgers, tacos, tortilla chips, and beer nuts." Some of the mothers mentioned unusual eating behaviors that had decreased or disappeared since childhood. One mother stated, "he liked oranges earlier than apples because the oranges were easier to eat since they're segmented. He used to eat the entire apple, including the core." Another mother explained "he used to eat the [hamburger] buns and then the patty, never together. Now he eats them together." Another mother described her son's preference for food mixed together: "I used to have to mix everything together, but he's better about that now; he'll eat some things separately."

When asked about which foods the participants did not like to eat, all participants responded that they disliked vegetables. Other dislikes included "spicy," "mashed potatoes," and "beef, lettuce, salads, pop, and mint." Reasons for disliking foods included texture of foods, smells, and taste. One participant described his dislike for beef and mint: "I won't eat beef because of how dangerous it is. Mint is an extreme example; I just have a funny reaction to it." His mother explained, “I can't even have chewing gum because he can't stand the smell. If he smells it he'll tell me to throw it out." When asked why he didn't like certain foods, one participant claimed, "probably the texture, the way it feels in your mouth. Like bananas." The SWEAA questionnaire responses again confirmed these adverse reactions to texture, with all participants answering sometimes correct, usually correct, or always correct to the following questions: "I am sensitive to the food's special texture" and "I prefer that the food has a 
smooth texture, as e.g. puree." Three of the participants answered sometimes correct or usually correct to the question "I am over sensitive to certain flavors."

\section{Change in Eating Habits and Preferences Over Time}

Most of the preferences that were specified by these individuals have been present since childhood. The food repertoire of the participants remains limited, but continues to improve as they try new foods. When asked how eating habits have changed, one participant responded, "they're improving, I'm trying new things." His mother interjected, "they're somewhat better, but he's always tried to try. The negative responses aren't as strong. We've added new things like spinach or lettuce, and he likes spicy stuff." Another mother echoed a similar sentiment when she stated, "he hasn't always had a large variety of foods, but he's better now. He has more variety now." One participant claimed that he has broadened his horizons, and his mother expanded this saying "pizza has always been in the mix. Foods change, but are still limited. As he's gotten older, he's

willing to broaden [his horizons]." As these participants try new foods, the variety of their diets improves. One participant tried kiwi in a day program, and will now eat kiwi on a consistent basis. Another example was a participant that tried his mother's seafood platter and then listed fish as a food that he loved to eat.

\section{Attitude Toward Trying New Foods}

Overall, participants had a neutral or reluctant attitude toward trying new foods. This attitude stems from negative experiences they have encountered in the past. One participant, when asked how he feels about trying new foods, described, "I am reluctant most of the time. There are certain times where 
something appeals or I feel brave enough to try something. I'm reluctant to try because of the number of things I have tried and didn't like." Another participant had a similar reaction, stating, "I'm not real enthusiastic about it. It's kind of difficult." His mother went on to explain, "when he was little he tried a couple of bites and he threw up." Another participant claimed he felt "okay," and that it "depends what it is." The willingness to try new foods was dependent upon reinforcement at home. One mother described the challenge of getting her son to try new foods, recounting, "I've always enforced the two-bite rule so that he didn't try to eliminate foods. It's important to be consistent with it and sometimes I felt bad about it." One participant claimed that he "loved" to try new foods, but his mother questioned his response saying, “He says he loves it, but I don't know how he really feels about it." She also revealed her tendency to provide foods and prepare foods in a way she knows he will eat. "I always mix the food together because I'm used to that and I know he'll eat it like that."

\section{Body Image and Weight}

Participants showed no concern for body image or weight. When asked how they felt about their bodies, the reaction was either neutral or positive. The mothers of the participants were attentive to weight, with three mothers noting weight gain as their sons aged. Two of the three mentioned a decrease in activity as a reason for weight gain. "Since he's gotten older and less active we've paid more attention to not gaining weight. He was really skinny when he was younger." Another mother responds similarly with "he's not concerned about weight. But he's put on a lot of weight in the last six months because he's been 
less active. And now that his brother is home [his brother] is bringing home a lot of food. He should be 300 pounds with the amount of food that he eats." Another mother also indicated that her son ate large portions of food, stating, "His idea of enough to eat and mine don't coincide." Two participants expressed interest in the purpose of the body rather than body image. "I'm more concerned about the functionality rather than appearance. In my mind, appearance means nothing." Another participant, when asked how he feels about his body, claimed he felt "good," and that he had "nothing to complain about, I don't get sick," mirroring the concern for functionality as opposed to appearance.

\section{Nutrition Knowledge and Physical Activity}

All participants had received some sort of nutrition education, and most were able to identify generally healthy foods. When asked by his mother what he should be eating, one participant responded, "Primarily fruits and vegetables, grains, and fish." Another participant, when asked what is not healthy, responded, "Candy, soda." Participants also mentioned their parents as a source of nutrition knowledge. Physical activity was varied among the participants. Some participants engaged in planned exercise such as running and swimming, while others did not engage in planned physical activity except daily activities that kept them active such as cleaning or pacing.

\section{Discussion}

The researchers in this study set out to answer three research questions: how have participants' eating habits changed over time, what eating patterns are currently present in their diet, and how do these eating patterns affect the 
participants' nutrient intake? Results were analyzed within the framework of Symbolic Interactionism (Smith \& Hammon, 2012).

Participants reported a limited selection of food preferences even after introducing new foods into their diets, suggesting that some of the feeding problems that exist in childhood continue into adulthood. Symbolic Interactionism recognizes that development is constantly changing. This seemed to be highly dependent on outside influences, such as day programs in which they were enrolled or encouragement from parents. Parents who focused on improving eating habits and made an effort to encourage their children to try new foods saw improvements in their children. These parents were also consistent despite the challenges this presented. Limited diet variety is perpetuated when parents become permissive and provide special meals (Hendy, Williams, Riegel, \& Candace, 2010).

The results of this study were inconsistent with previous findings stating that individuals with autism have difficulties gauging their satiety as a risk factor for obesity (Ho et al, 1997). Participants claimed to recognize whether they were feeling full or hungry, but did not always have good descriptors or an appropriate way of communicating these feelings. One participant described feeling full as no longer being able to eat, and another admitted to over eating in the past to the point of gagging. This raises the question about how these individuals define being full, but also suggests additional factors such as other behavioral, physical, and psychosocial influences that put these individuals at risk for becoming overweight or obese (Curtin, Anderson, Must, \& Bandini, 2010; Hinckson, 
Dickinson, Water, Sands, \& Penman, 2013; Ho, Eaves, \& Peabody, 1997; Phillips et al., 2014).

Participants showed no concern for body image, but the mothers began to express concern for weight gain as their sons aged; the mothers noted a change in metabolism and a decrease in physical activity. Perhaps individuals with ASD do not develop self identity the way that individuals without ASD do, and it has an effect on judgment of appearances. This relates back to the SI theory assumption of people reacting to something according to the meaning that thing has for them. While participants were not concerned with weight or body image, some of the mothers had taken steps to prevent weight gain, suggesting they are aware of the increased risk factors for developing obesity (Curtin, Anderson, Must, \& Bandini, 2010; Hinckson, Dickinson, Water, Sands, \& Penman, 2013; Ho, Eaves, \& Peabody, 1997; Phillips et al., 2014). The typical diets of the participants interviewed supports previous literature that has found children with autism consume higher amounts of low-nutrition, energy-dense foods (Evans et al., 2012). Participants were mainly consuming what would be considered a typical western diet high in carbohydrates and fat and low in fruits, vegetables, and fish. Food selectivity (by type, texture, and/or presentation) is one of the most common feeding problems associated with autism spectrum disorder (Williams et al., 2005) and this was reflected in the preferences of these participants. Participants avoided certain foods based on texture and taste, but the parents noted a decrease in negative responses and unusual eating behaviors as their children grew up, supporting the finding that autism symptoms are less severe 
among older individuals with autism spectrum disorder (Esbensen, Seltzer, Lam, \& Bodfish, 2009; Seltzer, Shattuck, Abbeduto, \& Greenberg, 2004; Shattuck et al., 2007).

Previous education was not particularly meaningful to the participants; some participants did not remember receiving any education until prompted by their mothers. However, participants had a general understanding about healthy eating. The ideas about healthy eating directly reflected the parents of the participants, suggesting that nutrition education needs to be emphasized at home in order to be effective. Feeding problems that these individuals face, such as textural issues, or reluctance to try new foods based on past negative experiences, presents a challenge to these individuals in consuming foods they consider healthy (Sharp et al., 2013). This could be explained by SI theory's concept that people derive meaning from what they believe, not what is objectively true (Crossman, 2015).

\section{Conclusions and Implications}

Results of this research suggest that methods of communication, internal and external environments, and content of nutrition education are factors that influence eating patterns of adults diagnosed with autism. Individuals with autism can gauge hunger and satiety but need to find appropriate ways of communicating these feelings. This is an area of education that can be focused on beginning in childhood. Being able to communicate hunger and determine fullness may prevent these individuals from overeating, and also helps to cue in 
to satiety signals. Awareness of satiety may improve as these individuals mature and needs to be continuously addressed as they age.

Food preferences are highly dependent upon influence from home environments and outside programs. These types of programs may provide individuals with ASD the opportunity to learn about different eating behaviors from interactions with peers. When participants are offered choices and encouraged to try new foods, they were more likely to consume a greater variety of foods. The decrease in negative responses to trying new foods that was reported as participants aged suggests the opportunity to develop good nutritional habits. Efforts should be made to consistently offer new foods to increase the variety in their diets, even if it is not successful the first few times. Eating a large variety of foods will reduce the risk of possible nutrient deficiencies.

The participants' concern with functionality rather than appearance should be considered in the way weight management is approached. When educating these individuals on the importance of nutrition, the physiological effect of food should be emphasized. The risk factors and comorbidities of obesity should also be discussed. Participant responses indicated that education provided in school was not memorable to these individuals; healthy eating principles therefore need to be reinforced at home in order for lessons to be effective. This becomes increasingly important as these individuals age because activity level decreases and metabolism slows. 
Adults with ASD face a variety of risk factors that increase their risk for obesity and related diseases, but focusing on ways to improve communication regarding hunger and satiety may reduce this risk factor. Promoting activity, offering healthy food options at home, and being consistent with encouraging them to try new foods will also help to reduce these risk factors. Eating habits tend to be highly individualized, and it is important to recognize the special needs and complexity of individuals with autism spectrum disorders.

Limitations of this study include a small sample size and a male-only population.

\section{Suggestions for Future Research}

Future research should focus on the long-term health implications of eating behaviors in individuals with ASD. It appears that individuals with ASD generally consume a high-energy, low-nutrient diet into adulthood. This finding could be further explored to see how this diet impacts their health as they age. Future research can also examine the relationship between the value that parents place on nutrition and health and the impact it has on their children with ASD. Diets could also be compared in adults with and without ASD to determine whether or not there is a significant difference in those with ASD. Another area to be further explored may include testing for specific deficiencies in children or adults with ASD. Lastly, different methods of nutrition education in individuals with autism can be studied to determine which is the most effective. 


\section{References}

Academy of Nutrition and Dietetics. (2015). Nutrition Care Manual. Retrieved from https://nutritioncaremanual.org/topic.cfm?ncm_category_id=1\&lv $1=255326$

\&lv2=255327\&ncm_toc_id $=255327 \& \mathrm{ncm} \_$heading=Nutrition $\% 20$ Care

American Psychiatric Association. (2013). Diagnostic and statistical manual of mental disorders ( $5^{\text {th }}$ ed.). Arlington, VA: American Psychiatric Publishing.

Ashworth, M., Hirdes, J.P., \& Martin, L. (2009). The social and recreational characteristics of adults with intellectual disability and pica living in institutions. Research in Developmental Disabilities, 30(3), 512-520.

Autism Spectrum Disorders. (2015). Centers for Disease Control and Prevention. Retrieved from: http://www.cdc.gov/ncbddd/autism/index.html

Bandini, L.G., Anderson S.E., Curtin, C., Cermak, S., Evans, E.W., Scampini, R.,... \& Must, A. (2010). Food selectivity in children with autism spectrum disorders and typically developing children. Journal of Pediatrics, 157(2), 259-264.

Baron-Cohen, S., Jaffa, T., Davies, S., Auyeung, B., Allison, C., \& Wheelwright, S.(2013). Do girls with anorexia nervosa have elevated autistic traits? Molecular Autism, 4(1), 1-8.

Crossman, A. (2015). Symbolic interaction theory. Retrieved from http://sociology.about.com/od/Sociological-Theory/a/SymbolicInteraction-Theory.htm

Curtin, C., Anderson, S.E., Must. A., \& Bandini, L. (2010). The prevalence of obesity in children with autism: A secondary data analysis using nationally representative data from the national survey of children's health. BMC Pediatrics, 10(11). doi:10.1186/1471-2431-10-11

Esbensen, A.J., Seltzer, M.M., Lam, K.S.L., \& Bodfish, J.W. (2009) Age-related differences in restricted repetitive behaviors in autism spectrum disorders. Journal of Autism and Developmental Disorders, 39(1), 57-66.

Evans, E.W., Must, A., Anderson, S.E., Curtin, C., Scampini, R., Maslin, M., \& Bandini, L. (2012). Dietary patterns and body mass index in children with autism and typically developing children. Research in Autism Spectrum Disorders, 6(1), 399-405.

Gillberg, C. (1983). Are autism and anorexia nervosa related? British Journal of Psychiatry, 142, 428.

Hendy, H.M., Williams, K.E., Riegel, K., \& Paul, C. (2010). Research report: Parent mealtime actions that mediate associations between children's fussy-eating and their weight and diet. Appetite, 54(1). 191-195.

Hinckson, E.A., Dickinson, A., Water, T., Sands, M., \& Penman, L. (2013). Physical activity, dietary habits and overall health in overweight and obese children and youth with intellectual disability or autism. Research in Developmental Disabilities, 34(4), 1170-1178. 
Ho, H.H., Eaves, L.C., \& Peabody, D. (1997). Nutrient intake and obesity in children with autism. Focus on Autism \& Other Developmental Disabilities, 12(3), 187-192.

Johnson, C.R., Handen, B.L., Mayer-Costa, M., \& Kelley, S. (2008). Eating habits and dietary status in young children with autism. Journal of Developmental \& Physical Disabilities, 20(5), 437-448.

Lacey, E.P. (1990). Broadening the perspective of pica: Literature review. Public Health Reports, 105(1), 29-35.

Mari-Bauset, S., Zazpe, I., Mari-Sanchis, A., Llopis-Gonzalez, A., \& MoralesSuarez,V.M. (2014). Evidence of the gluten-free and casein-free diet in autism spectrum disorders: A systematic review. Journal of Child Neurology. Advance online publication. http://jcn.sagepub.com

Panksepp, J. (1979). A neurochemical theory of autism. Trends in Neurosciences, 2.174-177. doi:10.1016/0166-2236(79)90071-7

Pennesi, C.M., \& Klein, L.C. (2012). Effectiveness of the gluten-free, casein-free diet for children diagnosed with autism spectrum disorder: Based on parental report. Nutritional Neuroscience, 15(2), 85-91.

Phillips, K., Schieve, L., Visser, S., Boulet, S., Sharma, A., Kogan, M., Boyle, C.,... Yeargin-Allsopp, M. (2014). Prevalence and impact of unhealthy weight in a national sample of adolescents with autism and other learning and behavioral disabilities. Maternal \& Child Health Journal, 18(8). 19641975.

Reynolds, A., Krebs, N.F., Stewart, P.A., Austin, H., Johnson, S.L., Withrow, N., \& Hyman, S.L. (2012). Iron status in children with autism spectrum disorder. Pediatrics, 130(2), 154-159.

Seltzer, M.M., Shattuck, P., Abbeduto, L., \& Greenberg, J.S. (2004). Trajectory of development in adolescents and adults with autism. Mental Retardation and Developmental Disabilities Research Reviews, 10(4), 234-247.

Sharp, W., Berry, R., McCracken, C., Nuhu, N., Marvel, E., Saulnier, C.,...\& Jaquess, D. (2013). Feeding problems and nutrient intake in children with autism spectrum disorders: A meta-analysis and comprehensive review of the literature. Journal of Autism \& Developmental Disorders, 43(9), 21592173.

Shattuck, P.T., Seltzer, M.M., Greenberg, J.S., Orsmond, G.I., Bolt, D., Kring, S.,...\& Lord,C. (2007). Change in autism symptoms and maladaptive behaviors in adolescents and adults with an autism spectrum disorder. Journal of Autism and Development Disorders, 37(9), 1735-1747.

Smith, S.R., \& Hamon R.R. (2012). Exploring family theories. Oxford University Press

Strauss, A., \& Corbin J. (1998). Basics of qualitative research: Techniques and procedures for developing grounded theory. Thousand Oaks, CA: SAGE Publications, Inc.

Weintraub, A.G. (2013, May 12). A history of autism. http://www.webmd.com /brain/aut ism/history-of-autism?page $=3$ 
What is Autism? (2014). Autism Speaks. Retrieved from http://www.autismspe aks.org /what-autism

Williams, K., Gibbons, B., \& Schreck, K. (2005). Comparing selective eaters with and without developmental disabilities. Journal of Developmental \& Physical Disabilities, 17(3), 299-309.

Xia, W., Zhou, Y., Sun, C., Wang, J., \& Wu, L. (2010). A preliminary study on nutritional status and intake in Chinese children with autism. European Journal of Pediatrics, 169(10), 1201-1206.

Zimmer, M.H., Hart, L.C., Manning-Courtney, P., Murray, D.S., Bing, N.M., \& Summer,S. (2012). Food variety as a predictor of nutritional status among children with autism. Journal of Autism and Developmental Disorders, 42(4), 549-556. 


\section{CHAPTER II}

\section{EXTENDED LITERATURE REVIEW}

Autism spectrum disorders (ASD) include Asperger's syndrome, pervasive developmental disorder, not otherwise specified (PDD-NOS), and autistic disorder. There are an additional two types of autism, Rett syndrome and childhood disintegrative disorder, that are rare and severe conditions that fall under the category of autism spectrum disorders. ASD affects social interactions, communication, and behaviors and interests (Weintraub, 2013). Children with ASD experience feeding problems and food selectivity is particularly problematic (Sharp et al., 2013). ASD is complex and no two individuals with autism spectrum disorders are alike.

\section{Research Directions}

Much of the previous research on autism has focused on children, as they are developing and any nutrient deficiencies may have serious consequences during this critical time of development. However, there is a gap in the literature regarding adults living with ASD. Sharp et al. (2013) emphasized the need for future research to address the long-term impact of atypical feeding and also encouraged researchers to extend the net of inquiry to include additional related outcomes. During the International Meeting for Autism Research in 2014, 
researchers acknowledged that adults are vastly underrepresented in autism research. Researchers Williams, Gibbons, and Schreck (2005) recognized that selective eating and feeding problems associated with ASD in children are not ephemeral. It is unknown whether these similar behaviors are found in adults. While this is a difficult area to study due to individual variances and conflicting conclusions of previous research, it is important to determine if these atypical eating behavior patterns continue into adulthood and if so, what the consequences of these behavior patterns may be. This study contributes insight into feeding behaviors and long-term impacts of an adult living with ASD.

\section{Nutritional Status in Individuals with Autism}

Rigid adherence to certain foods is a common characteristic in individuals with autism and may lead to nutrient deficiencies. Individuals with ASD tend to have restrictive eating behaviors that could put them at risk for nutrient deficiencies, and nutrition status in individuals with ASD has been a heavily researched area. In a study conducted using a 3-day food record and body mass index (BMI) in children with ASD compared to a matched control, researchers found that children with ASD consumes less than the recommended amounts of certain nutrients from food such as fiber, choline, calcium, vitamin $\mathrm{D}$, vitamin $\mathrm{K}$, and potassium (Zimmer, Hart, Manning-Courtney, Murray, Bing, \& Summer, 2012). However, the researchers noted that other children in America not diagnosed with ASD also consumed less than the recommended amounts of certain nutrients. The children with ASD consumed similar amounts of nutrients from food compared to the matched controls in the study. 
Another study performed concluded that children with autism had more mealtime behavioral differences, but these did not translate to significant differences in nutritional status compared to typically developing children (Johnson, et al., 2008). The limitations in the study were listed as a small sample size, failure to account for the variability of food intake across several days, and there was much variability within both groups. Despite the noted limitations, the results of these two studies raise the question of whether or not food selectivity patterns result in altered nutritional status in individuals with ASD. Researchers in China using a 3-day food record found several deficiencies in the intakes of several vitamins and essential nutrients, despite satisfactory growth in the vast majority of the children. However, individual intakes were difficult to accurately obtain because families in China have a tradition of sharing dishes at mealtimes (Xia et al., 2010).

Iron status is a specific area that has been examined by researchers because previous studies have demonstrated a high prevalence of iron deficiency in children with ASD. In a clinical sample containing 122 children, iron deficiency and iron deficiency anemia were more common in children with ASD than the general population (Sidrak, Yoong, \& Woolfenden, 2014). However, Reynolds et al. (2012) determined that their data did not support previous reports that children with ASD are at greater risk for iron deficiency than the general population, despite a small percentage of their sample demonstrating low serum ferritin. Despite these conflicting conclusions, it could be suggested that ferritin 
levels be routinely measured in this population due to the role iron plays in cognitive, behavioral, and motor development.

\section{Food Selectivity in Individuals with Autism}

According to the National Institutes of Health (2013), two of the indicators used to diagnose ASD are engaging in repetitive movements or behaviors and inflexible adherence to specific routines or rituals. These patterns of behavior may be reflected in eating patterns of individuals diagnosed with ASD. A metaanalysis determined that children with ASD experienced significantly more feeding problems when compared to their peers (Sharp et al., 2013). Food selectivity is one of the most commonly reported feeding problems in children with autism (Bandini et al., 2010; Field, Garland, \& Williams, 2003; Klintwall et al., 2011; Legge, 2002). Food selectivity is often based on types or textures of foods (Field et al., 2003). Feeding problems, such as refusal to eat or eating a small range of food, and food selectivity may put them at risk for nutritional deficiencies (Bandini et al., 2010). This area of research can be difficult to explore due to variances in food choices among individuals. Nutrient deficiencies may be difficult to determine because of these variances in food choices and may explain differing results in research.

\section{Eating Disorders in Individuals with Autism}

The idea that there was a connection between anorexia nervosa (AN) and autism spectrum disorders was initially suggested by Gillberg (1983), and has since been explored because of the similar cognitive style and commonalities in behaviors such as repetitive actions, preference for routines, perfectionism, and 
fixation on details. The idea that anorexia and autism are comorbid (Gillberg, Rastam, Wentz, \& Gillberg, 2007) has been further investigated in studies measuring elevated autistic traits in girls with anorexia. These studies revealed that on average girls with anorexia struggle with social skills and empathy difficulties as well as narrow interests and resistance to change, mirroring behaviors seen in autism (Baron-Cohen et al., 2013; Tchanturia, 2013). Adolescent girls reported more eating problems indicative of an eating disorder in those diagnosed with Asperger syndrome than without the diagnosis (Kalvya, 2009). The link between anorexia and autism, demonstrated by underlying behavioral and cognitive similarities such as rigid behaviors, pre-occupation with the self, attention to detail, and failure to empathize, continues to be an area of interest (Baron-Cohen et al., 2013).

\section{Obesity in Individuals with Autism}

Another area of interest is weight status in individuals with ASD. Because of idiosyncratic eating behaviors that are difficult to regulate, among other factors, such as medications, atypical sleep patterns, and lower levels of physical activity, individuals with ASD are at a high risk for developing obesity (Curtin, Anderson, Must, \& Bandini, 2010; Hinckson, Dickinson, Water, Sands, \& Penman, 2013; Ho, Eaves, \& Peabody, 1997; Phillips et al., 2014). These individuals face a variety of risk factors that in general developing children may not face. One factor that may contribute to overeating and obesity is the ready access to food at home, because individuals with ASD may not be able to live independently depending on the severity of their diagnosis. They also may not 
understand the consequences of obesity and may not be able to gauge their satiety (Ho et al., 1997). Another factor contributing to obesity is a diet consisting of low-nutrition, energy-dense foods. Research has found children with ASD consume more sweetened beverages and snacks and fewer fruits and vegetables than typical developing children (Evans et al., 2012). Finally, children with autism lack social motivation, possibly preventing them from participating in family meals or structured activities (Lee, Harrington, \& Newschaffer, 2008). This combination of unique factors puts them at a higher risk of developing obesity and possibly other related diseases.

\section{Recommended Diets: Gluten-Free, Casein-Free Diet}

One diet that is currently recognized in the Nutrition Care Manual for individuals diagnosed with ASD is the Gluten-Free, Casein-Free Diet. This elimination diet has gained popularity recently and is believed to reduce symptoms of autism and improve social and cognitive behaviors. Gluten is found in wheat, barley, and rye, while casein is found in dairy products. The belief is that ASD children may be allergic or sensitive to gluten and casein found in these food products (NCM Website, 2015).

Increased intestinal permeability is reported in individuals with autism (D'Eufemia et al., 1996). A subgroup of diagnosed individuals may have intestinal abnormalities that allow incompletely digested peptides of casein and gluten to enter the bloodstream (NCM Website, 2015). Advocates of the opioid excess theory hypothesize that autistic children are especially sensitive to gluten and casein, resulting in small bowel inflammation. The opioid excess theory 
postulates that autism arises from opiate disruption in the brain. Casomorphin, gluten exorphin, gliadorphin/gluteomorphin are opioid food peptides that bind to opioid receptors and have a variety of effects in the neurotransmitter systems of the brain. Panksepp (1979) proposed the idea that childhood autism may be caused by overactivity of the child's brain opiate system.

Several studies have noted that there were no statistically significant differences in children with ASD who had tried the GFCF diet, however, parents did note that there were improvements in their children's symptoms or behaviors (Elder et al., 2006; Johnson et al., 2010; Pennesi et al., 2012). Knivsberg, Reichelt, Hoien, \& Nodland (2002) evaluated the effect of the gluten-free, caseinfree diet and noted a significant reduction of autistic behavior. It has also been reported that adherence to the diet is difficult, likely due to the restriction and limitation of food choices (Johnson, Handen, Zimmer, Sacco, \& Turner, 2010).

Previous research has produced mixed results, and its effectiveness on reducing symptoms still requires further research (Pennesi \& Klein, 2012). A recent review concluded that current evidence is limited and weak, and researchers recommended implementing the GFCF diet only after a diagnosis of an intolerance or allergy to these foods has been made (Mari-Bauset, Zazpe, Mari-Sanchis, Llopis-Gonzalez, \& Morales-Suarez, 2014).

\section{Similarities with Other Diseases and Disorders}

There is some overlap in social and behavioral abnormalities between ASD and other diseases such as Alzheimer's, dementia, and schizophrenia. While a direct comparison between eating behaviors in these diseases is not a 
heavily studied area, there has been some investigation into differences and similarities. Some similarities found in schizophrenia include medications possibly contributing to obesity, low intake of fruits and vegetables, a lack of variety, and a preference for routine (Hardy \& Gray, 2012). Similarities in Alzheimer's and dementia include inadequate micronutrient intake, mealtime difficulties, eating abnormalities, decreased independence, refusal to eat or avoidance of foods, and eating non-food items (Goes et al., 2014; Edahiro et al., 2012; Durnbaugh, Haley, \& Roberts, 1996). Exploring similarities in eating behaviors in other diseases and disorders can provide insight into treatment and care for ASD individuals.

\section{Pica in Autism}

Pica is the persistent craving and eating of non-food substances, such as dirt or paint that can be harmful or lead to other complications. The DSM IV-TR diagnostic criteria for pica includes a. persistent eating of nonnutritive substances for a). period of at least 1 month, b). the eating of nonnutritive substances is inappropriate to the developmental level, c). the eating behavior is not part of a culturally sanctioned practice, and d). if the eating behavior occurs exclusively during the course of another mental disorder, it is sufficiently severe to warrant independent clinical attention (American Psychiatric Association, 2013). It has been recognized that individuals with autism are at risk for developing other challenging behaviors such as pica, but the relationship between pica and autism is not clearly understood. The prevalence of pica in individuals with intellectual disabilities living in institutional settings has been reported to be between 5.7 and 
$25.8 \%$ but is relatively rare among those residing in the community (Ashworth, Hirdes, \& Martin, 2009). Pica is of concern due to the possibly severe medical consequences from even just one instance (Lacey, 1990).

\section{Aging with Autism Spectrum Disorders}

Due to minimal research in adults with autism, it is not well known how aging affects symptoms and characteristics of autism. In a longitudinal study spanning ten years, it was found that the transition from adolescence to adulthood is a time of amplified risk for individuals with ASD. The results of this study indicated that level of independence significantly declined over the ten-year period (Taylor \& Mailick, 2014). It is possible that certain symptoms decline with development, and researchers have found that repetitive behaviors were less frequent and less severe in the older population than the younger population, supporting previous findings that autism symptoms are less severe among older individuals with ASD (Esbensen, Seltzer, Lam, \& Bodfish, 2009; Seltzer, Shattuck, Abbeduto, \& Greenberg, 2004; Shattuck et al., 2007). How these changes in symptoms affect eating habits is not yet known. As the ever-growing population of children with autism begins to age, it is important to understand what their long-term care needs may be.

\section{The Swedish Eating Assessment for ASD}

The Swedish eating assessment (SWEAA) is a self-report questionnaire that was developed by Karlsson, Rastam, \& Wentz (2013) as a tool to investigate eating and mealtime problems in individuals with ASD and normal intelligence. Initial validity and reliability tests have shown promising results and the tool offers 
an opportunity to gain insight into some of the most common behavioral problems in individuals with ASD. The questionnaire also allows researchers to be aware of eating disturbances present in participants. The subscales of the SWEAA include perception, motor control, purchase of food, eating behavior, mealtime surroundings, social situation at mealtime, other behavior associated with disturbed eating, and hunger/satiety. Single items include simultaneous capacity and pica. This newly developed tool provides good insight into eating behaviors in individuals with ASD. 


\section{References}

Academy of Nutrition and Dietetics. (2013). Nutrition Care Manual. Retrieved from https://nutritioncaremanual.org/topic.cfm?ncm_category_id=1\&lv1=2 55326 \&lv2=255327\&ncm_toc_id=255327\&ncm_heading=Nutrition $\% 2$ 0Care

American Psychiatric Association. (2013). Diagnostic and statistical manual of mental disorders ( $5^{\text {th }}$ ed.). Arlington, VA: American Psychiatric Publishing.

Ashworth, M., Hirdes, J.P., \& Martin, L. (2009). The social and recreational characteristics of adults with intellectual disability and pica living in institutions. Research in Developmental Disabilities, 30(3), 512-520.

Autism Spectrum Disorders. (2014). Centers for Disease Control and Prevention. Retrieved from: http://www.cdc.gov/ncbddd/autism/index.html

Bandini, L.G., Anderson S.E., Curtin, C., Cermak, S., Evans, E.W., Scampini, R.,...\& Must, A. (2010). Food selectivity in children with autism spectrum disorders and typically developing children. JOURNAL OF PEDIATRICS, 157(2), 259-264.

Baron-Cohen, S., Jaffa, T., Davies, S., Auyeung, B., Allison, C., \& Wheelwright, S.(2013). Do girls with anorexia nervosa have elevated autistic traits? Molecular Autism, 4(1), 1-8.

Curtin, C., Anderson, S.E., Must. A., \& Bandini, L. (2010). The prevalence of obesity in children with autism: A secondary data analysis using nationally representative data from the national survey of children's health. BMC Pediatrics, 10(11). doi:10.1186/1471-2431-10-11

D’Eufemia, P. Celli, M., Finocchiaro, R., Pacifico, L, Viozzi, L., Zaccagnini, M., ... \& Giardini, O. (1996). Abnormal intestinal permeability in children with autism. Acta Paediatrica, 85(9). 1076-1079.

Durnbaugh, T., Haley, B., \& Roberts, S. (1996). Assessing problem feeding beahviors in mid-stage alzheimer's disease: Clients with mid-stage alzheimer's disease may be eating far less than their caregivers believe. Geriatric Nursing, 17(2), 63-67.

Edahiro, A., Hirano, H., Yamada, R., Chiba, Y., Watanabe, Y., Tonogi, M., \& Yamane, G.Y. (2012). Factors affecting independence in eating among elderly with alzheimer's disease. Geriatrics \& Gerontology International, 12(3), 481-490.

Elder, J.H., Shankar, M., Shuster, J., Therique, D., Burns, S., \& Sherrill, L. (2006). The gluten-free, casein-free diet in autism: Results of a preliminary double clinical trial. Journal of Autism and Developmental Disorders, 36(3), 413-420.

Esbensen, A.J., Seltzer, M.M., Lam, K.S.L., \& Bodfish, J.W. (2009) Age-related differences in restricted repetitive behaviors in autism spectrum disorders. Journal of Autism and Developmental Disorders, 39(1), 57-66.

Evans, E.W., Must, A., Anderson, S.E., Curtin, C., Scampini, R., Maslin, M., \& Bandini, L. (2012). Dietary patterns and body mass index in children with 
autism and typically developing children. Research in Autism Spectrum Disorders, 6(1),399-405.

Field, D., Garland, M., \& Williams, K. (2003). Correlates of specific childhood feeding problems. Journal of Paediatrics \& Child Health, 39(4), 299-304.

Gillberg, C. (1983). Are autism and anorexia nervosa related? British Journal of Psychiatry, 142, 428.

Gillberg, C., Rastam, M., Wentz, E., \& Gillberg, C. (2007). Cognitive and executive functions in anorexia nervosa ten years after onset of eating disorder. Journal of Clinical and Experimental Neuropsychology, 29(2), 170-178.

Goes, V.F., Mello-Carpes, P.B., Oliveira, L.O., Hack, J., Magro, M., \& Bonini, J.S. (2014). Evaluation of dysphagia risk, nutritional status and caloric intake in elderly patients with alzheimer's. Revista Latino-Americana de Enfermagem, 22(2), 317-324.

Hardy, S., \& Gray, R. (2012). The secret food diary of a person diagnosed with schizophrenia. Journal of Psychiatric \& Mental Health Nursing, 19(7), 603609.

Hendy, H.M., Williams, K.E., Riegel, K., \& Paul, C. (2010). Research report: Parent mealtime actions that mediate associations between children's fussy-eating and their weight and diet. Appetite, 54(1). 191-195.

Hinckson, E.A., Dickinson, A., Water, T., Sands, M., \& Penman, L. (2013). Physical activity, dietary habits and overall health in overweight and obese children and youth with intellectual disability or autism. Research in Developmental Disabilities, 34(4), 1170-1178.

Ho, H.H., Eaves, L.C., \& Peabody, D. (1997). Nutrient intake and obesity in children with autism. Focus on Autism \& Other Developmental Disabilities, 12(3), 187- 192.

Johnson, C.R., Handen, B.L., Mayer-Costa, M., \& Kelley, S. (2008). Eating habits and dietary status in young children with autism. Journal of Developmental \& Physical Disabilities, 20(5), 437-448.

Johnson, C.R., Handen, B.L., Zimmer, M., Sacco, K., \& Turner, K. (2010). Effects of gluten free/casein free diet in young children with autism: A pilot study. Journal of Developmental and Physical Disabilities, 23(3), 213-225.

Kalvya, E. (2008). Comparison of eating attitudes between adolescent girls with and without Asperger syndrome: Daughters' and mothers' reports. Journal of Autism \& Developmental Disorders, 39(3), 480-486.

Karlsson, L., Rastam, M., \& Wentz, E. (2013). The Swedish eating assessment for autism spectrum disorders-Validation of a self-report questionnaire targeting eating disturbances within the autism spectrum disorders. Research in Developmental Disabilities, 34(7), 2224-2233.

Klintwall, L., Holm, A., Eriksson, M., Carlsson, L.H., Olsson, M.B., Hedvall, A.,...\& Fernell, E. (2011). Sensory abnormalities in autism: A brief report. Research in Developmental Disabilities: A Multidisciplinary Journal, 32(2), 795-800. 
Knivsberg, A.M., Reichelt, K.L., Hoien, T., \& Nodland, M. (2002). A randomised, controlled study of dietary intervention in autistic syndromes. Nutritional Neuroscience, 5(4). 251-261.

Lacey, E.P. (1990). Broadening the perspective of pica: Literature review. Public Health Reports, 105(1), 29-35.

Lee, L.C., Harrington, R., A., Louie, B.B., \& Newschaffer, C.J. (2008). Children with autism: Quality of life and parental concerns. Journal of Autism \& Developmental Disorders, 38(6), 1147-1160

Legge, B. (2002). Can't eat, won't eat: Dietary difficulties and autistic spectrum disorders. London: Jessica Kingsley Publishers.

Mari-Bauset, S., Zazpe, I., Mari-Sanchis, A., Llopis-Gonzalez, A., \& MoralesSuarez, V.M. (2014). Evidence of the gluten-free and casein-free diet in autism spectrum disorders: A systematic review. Journal of Child Neurology. Advance online publication. http://jcn.sagepub.com

National Institute of Neurological Disorders and Stroke. (2013). Autism Fact Sheet. Retrieved from http://www.ninds.nih.gov/disorders/autism/deta il_autism .htm

Pennesi, C.M., \& Klein, L.C. (2012). Effectiveness of the gluten-free, casein-free diet for children diagnosed with autism spectrum disorder: Based on parental report. Nutritional Neuroscience, 15(2), 85-91.

Phillips, K., Schieve, L., Visser, S., Boulet, S., Sharma, A., Kogan, M., Boyle, C.,...\& Yeargin-Allsopp, M. (2014). Prevalence and impact of unhealthy weight in a national sample of adolescents with autism and other learning and behavioral disabilities. Maternal \& Child Health Journal, 18(8). 19641975.

Reynolds, A., Krebs, N.F., Stewart, P.A., Austin, H., Johnson, S.L., Withrow, N., \& Hyman, S.L. (2012). Iron status in children with autism spectrum disorder. Pediatrics, 130(2), 154-159.

Seltzer, M.M., Shattuck, P., Abbeduto, L., \& Greenberg, J.S. (2004). Trajectory of development in adolescents and adults with autism. Mental Retardation and Developmental Disabilities Research Reviews, 10(4), 234-247.

Sharp, W., Berry, R., McCracken, C., Nuhu, N., Marvel, E., Saulnier, C.,...\& Jaquess, D. (2013). Feeding problems and nutrient intake in children with autism spectrum disorders: A meta-analysis and comprehensive review of the literature. Journal of Autism \& Developmental Disorders, 43(9), 21592173.

Shattuck, P.T., Seltzer, M.M., Greenberg, J.S., Orsmond, G.I., Bolt, D., Kring, S.,...\& Lord, C. (2007). Change in autism symptoms and maladaptive behaviors in adolescents and adults with an autism spectrum disorder. Journal of Autism and Development Disorders, 37(9), 1735-1747.

Smith, S.R., \& Hamon R.R. (2012). Exploring Family Theories. Oxford University Press

Strauss, A., \& Corbin J. (1998). Basics of qualitative research: Techniques and procedures for developing grounded theory. Thousand Oaks, CA: SAGE Publications, Inc. 
Taylor, J.L., \& Mailick, M.R. (2014). A longitudinal examination of 10-year change in vocational and educational activities for adults with autism spectrum disorders. Developmental Psychology, 50(3), 669-708.

Tchanturia, K., Smith, E., Weineck, F., Fidanboylu, E., Kern, N., Treasure, J., \& Baron-Cohen, S. (2013). Exploring autistic traits in anorexia: A clinical study. Molecular Autism, 4(1), 2-20.

Weintraub, A.G. (2013, May 12). A History of Autism. http://www.webmd.com/ brain/autism/history-of-autism?page $=3$

What is Autism? (2014). Autism Speaks. Retrieved from http://www.autismsp eaks.org /what-autism

Williams, K., Gibbons, B., \& Schreck, K. (2005). Comparing selective eaters with and without developmental disabilities. Journal of Developmental \& Physical Disabilities, 17(3), 299-309.

Xia, W., Zhou, Y., Sun, C., Wang, J., \& Wu, L. (2010). A preliminary study on nutritional status and intake in Chinese children with autism. European Journal of Pediatrics, 169(10), 1201-1206.

Zimmer, M.H., Hart, L.C., Manning-Courtney, P., Murray, D.S., Bing, N.M., \& Summer. (2012). Food variety as a predictor of nutritional status among children with autism. Journal of Autism and Developmental Disorders , 42(4), 549- 556. 


\section{APPENDIX A}

\section{PARTICIPANT CONSENT FORM}




\section{LETTER OF CONSENT FOR ADULTS}

Dear

I am a graduate student completing a thesis study under the direction of Dr. Banning in the Department of Family and Consumer Sciences in the College of Applied Science and Technology at Illinois State University. I am conducting a research study to explore the relationship between food and autism. I am requesting your participation, which will involve participation in an interview and agreement to fill out a questionnaire. The duration of participation is expected to be no longer than two hours. You may skip any questions you do not wish to answer.

Your participation in this study is voluntary. If you choose not to participate or to withdraw from the study at any time, there will be no penalty. Your responses are confidential and any information that might allow someone to identify you will not be disclosed.

There are no risks involved with participation beyond those of everyday life. Although there may be no direct benefit to you, a possible benefit of your participation is gaining insight into your eating behaviors and patterns.

If you have any questions concerning the research study, please call me at (630) 888-2286 or Dr. Banning at (309) 438-5960

Sincerely, Samantha Barbier

I consent to participating in the above study.

Signature Date

Legally authorized representative:

Date:

If you have any questions about your rights as a subject/participant in this research, or if you feel you have been placed at risk, you can contact the Research Ethics \& Compliance Office at Illinois State University at (309) 4382529. 
APPENDIX B

\section{PARTICIPANT INTERVIEW QUESTIONS}




\section{Interview Questions}

- How does your body feel before you eat?

- How does your body feel after you eat?

- What foods do you love to eat?

- When did you start liking this food?

- How do you feel about trying new foods?

- How have your eating habits changed since you were younger?

- What foods do you not like to eat?

$\circ$ Why do you not like these foods?

- How much physical activity do you get per week?

- What do you like to do for physical activity?

- How do you feel about your body?

- Are you concerned about weight?

- What do you know about eating healthy?

- Has anybody talked to you before about eating healthy? 


\section{APPENDIX C}

\section{SWEDISH EATING ASSESSMENT FOR AUTISM SPECTRUM DISORDERS}




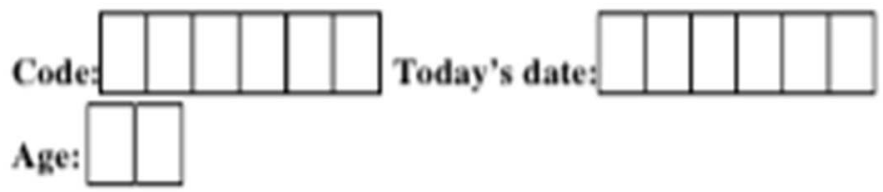

Tick one option per line:

$\square$ Girlwoman $\square$ Boy/man

I live alone $\square$ I live together with ocher psople

I go to: $\square$ junior high school $\square$ high school $\square$ folk high school $\square$ collegeluniversity $\square$ do not study

Tick one or multiple options:

I have completed: $\square$ middle school $\square$ junior high scbool $\square$ high school $\square$ folk high school $\square$ collegeluniversity

Tick the option that is most appropriate:

A

\begin{tabular}{lllll}
$\begin{array}{l}\text { never } \\
\text { correct }\end{array}$ & $\begin{array}{l}\text { seldom } \\
\text { correct }\end{array}$ & $\begin{array}{l}\text { sometimes } \\
\text { correct }\end{array}$ & $\begin{array}{l}\text { usually } \\
\text { correct }\end{array}$ & $\begin{array}{l}\text { always } \\
\text { correct }\end{array}$ \\
\hline
\end{tabular}

1. I am plagued by food smells, c.g. I must

leave the room or the meal due to the smell

2. I am over sensitive to certain flavours

3. I find it difficult to tell what the food tastes like

4. I am sensitive to the food's special texture

5. I prefer that the food has a smooth texture, as es. purce

6. I find it difficult to cat dishes where several ingredients are mixed, e.g. stews

7. I am disturbed by the sound of when 1 cbew certain food, e.g. Swedish cracker

8. I am disturbed by the sounds others make ahen eating

9. I am disturbed by othet people talking while I am eating

10. It is important that the food is sorted on the plate

11. I ex the food on the plate in a certain

ofder (e.g. first meat, tben potatoes)

$\square$
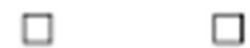

$\square$

$\square$

ㅁ

$\square$

$\square$

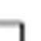

口 


\begin{tabular}{|c|c|c|c|c|c|}
\hline$\underline{\mathbf{B}}$ & $\begin{array}{l}\text { never } \\
\text { correct }\end{array}$ & $\begin{array}{l}\text { seldom } \\
\text { correct } \\
\end{array}$ & $\begin{array}{l}\text { sometimes } \\
\text { correct }\end{array}$ & $\begin{array}{l}\text { usually } \\
\text { correct }\end{array}$ & $\begin{array}{l}\text { always } \\
\text { correct }\end{array}$ \\
\hline 1. I find it difficult to chew & $\square$ & $\square$ & $\square$ & $\square$ & $\square$ \\
\hline 2. 1 am drooling during the meal & $\square$ & $\square$ & $\square$ & $\square$ & $\square$ \\
\hline $\begin{array}{l}\text { 3. I get food around tbe mouth while } \\
1 \text { am eating }\end{array}$ & $\square$ & $\square$ & $\square$ & $\square$ & $\square$ \\
\hline 4. I find it difficult to swallow & $\square$ & $\square$ & $\square$ & $\square$ & $\square$ \\
\hline 5. 1 spill wben 1 eat & $\square$ & $\square$ & $\square$ & $\square$ & $\square$ \\
\hline 6. I have good table manners & $\square$ & $\square$ & $\square$ & $\square$ & $\square$ \\
\hline 3. I drink out of a glass witbout spilling & $\square$ & $\square$ & $\square$ & $\square$ & $\square$ \\
\hline \multicolumn{6}{|l|}{$\underline{\mathbf{C}}$} \\
\hline $\begin{array}{l}\text { 1. I buy groceries from a special } \\
\text { supermarket/business chain }\end{array}$ & $\square$ & $\square$ & $\square$ & $\square$ & $\square$ \\
\hline 2. My food must be of a certain brand & $\square$ & $\square$ & $\square$ & $\square$ & $\square$ \\
\hline $\begin{array}{l}\text { 3. If I buy food with someone else, I want } \\
\text { to chect what goods are purchased }\end{array}$ & $\square$ & $\square$ & $\square$ & $\square$ & $\square$ \\
\hline
\end{tabular}

1. I prefer certain food depending on the colour of the food

2. I eat the same food every day

3. I awoid trying new foodinew dishes

4. I only eat a limited menu, maximum of 10 dishes

5. I eat smaller amounts of food than ochers

6. I drink excessive fluids

$\square$

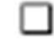

$\square$ 


\begin{tabular}{|c|c|c|c|c|c|}
\hline & $\begin{array}{l}\text { never } \\
\text { correct }\end{array}$ & $\begin{array}{l}\text { seldom } \\
\text { correct } \\
\end{array}$ & $\begin{array}{l}\text { sometimes } \\
\text { correct }\end{array}$ & $\begin{array}{l}\text { usually } \\
\text { correct } \\
\end{array}$ & $\begin{array}{l}\text { always } \\
\text { correct } \\
\end{array}$ \\
\hline 4. I get ourbursts a the dinner table & $\square$ & $\square$ & $\square$ & $\square$ & $\square$ \\
\hline 5. I whine at the dinner table & $\square$ & $\square$ & $\square$ & $\square$ & $\square$ \\
\hline $\begin{array}{l}\text { 6. I find it difficult to cat at school/ } \\
\text { workplace/activity centre of } \\
\text { simalar }\end{array}$ & $\square$ & $\square$ & $\square$ & $\square$ & $\square$ \\
\hline $\begin{array}{l}\text { 7. I find it difficult to eat with } \\
\text { relatives }\end{array}$ & $\square$ & $\square$ & $\square$ & $\square$ & $\square$ \\
\hline 8. I find it difficult to eal with friends & $\square$ & $\square$ & $\square$ & $\square$ & $\square$ \\
\hline 9. I find it difficult to eat in the café & $\square$ & $\square$ & $\square$ & $\square$ & $\square$ \\
\hline $\begin{array}{l}\text { 10. I find it difficult to eat in a } \\
\text { restaurant }\end{array}$ & $\square$ & $\square$ & $\square$ & $\square$ & $\square$ \\
\hline $\begin{array}{l}11.1 \text { find it difficult to eat when } 1 \\
\text { am abroad }\end{array}$ & $\square$ & $\square$ & $\square$ & $\square$ & $\square$ \\
\hline \multicolumn{6}{|l|}{$\underline{\mathbf{F}}$} \\
\hline $\begin{array}{l}\text { 1. I eat together with the ondiones } \\
1 \text { live with }\end{array}$ & $\square$ & $\square$ & $\square$ & $\square$ & $\square$ \\
\hline 2. I est in my bedroom & $\square$ & $\square$ & $\square$ & $\square$ & $\square$ \\
\hline $\begin{array}{l}\text { 3. I adapt my behaviour to others } \\
\text { who sit around the table (e.g. } \\
\text { table manners, conversatioa) }\end{array}$ & $\square$ & $\square$ & $\square$ & $\square$ & $\square$ \\
\hline $\begin{array}{l}\text { 4. I like company around } \\
\text { a msal }\end{array}$ & $\square$ & $\square$ & $\square$ & $\square$ & $\square$ \\
\hline 5. I talk during the meal & $\square$ & $\square$ & $\square$ & $\square$ & $\square$ \\
\hline $\begin{array}{l}\text { 6. I look down at my food most } \\
\text { of the time during the meal }\end{array}$ & $\square$ & $\square$ & $\square$ & $\square$ & $\square$ \\
\hline $\begin{array}{l}\text { 7. I say if I think the food is good } \\
\text { (when I am invited for a maal) }\end{array}$ & $\square$ & $\square$ & $\square$ & $\square$ & $\square$ \\
\hline $\begin{array}{l}\text { 8. I thank prople for the food } \\
\text { (uben I have been invited for a meal) }\end{array}$ & $\square$ & $\square$ & $\square$ & $\square$ & $\square$ \\
\hline 9. I cat with a knife and fork & $\square$ & $\square$ & $\square$ & $\square$ & $\square$ \\
\hline $\begin{array}{l}\text { 10. I leave the table as soon as the } \\
\text { food is eaten }\end{array}$ & $\square$ & $\square$ & $\square$ & $\square$ & $\square$ \\
\hline
\end{tabular}




\begin{tabular}{|c|c|c|c|c|c|}
\hline G & $\begin{array}{l}\text { never } \\
\text { correct }\end{array}$ & $\begin{array}{l}\text { seldom } \\
\text { correct }\end{array}$ & $\begin{array}{l}\text { sometimes } \\
\text { correct }\end{array}$ & $\begin{array}{l}\text { usually } \\
\text { correct }\end{array}$ & $\begin{array}{l}\text { always } \\
\text { correct }\end{array}$ \\
\hline 1. I iscluce vomiting after meals & $\square$ & $\square$ & $\square$ & $\square$ & $\square$ \\
\hline 2. I use diuretics & $\square$ & $\square$ & $\square$ & $\square$ & $\square$ \\
\hline 3. I use diet pills & $\square$ & $\square$ & $\square$ & $\square$ & $\square$ \\
\hline $\begin{array}{l}\text { 4. I diet even if other people think I } \\
\text { am too thin }\end{array}$ & $\square$ & $\square$ & $\square$ & $\square$ & $\square$ \\
\hline 5. I fast & $\square$ & $\square$ & $\square$ & $\square$ & $\square$ \\
\hline $\begin{array}{l}\text { 6. I am replacing mrals with nutritional } \\
\text { drinkspowder }\end{array}$ & $\square$ & $\square$ & $\square$ & $\square$ & $\square$ \\
\hline $\begin{array}{l}\text { 3. It is important that one person } \\
\text { (the ssme person) prepares my food }\end{array}$ & $\square$ & $\square$ & $\square$ & $\square$ & $\square$ \\
\hline 8. I refuse to cat & $\square$ & $\square$ & $\square$ & $\square$ & $\square$ \\
\hline
\end{tabular}

H

1. I foel uben 1 am bangry

2. I feel aben I am full

$\underline{I}$

1. I find it difficult to do two things simvaltaneously during a meal, e.g.

chewing and cutting the food

$\underline{\mathbf{J}}$

1. I eat things that others consider inedible (e.g. mortar or soil)

$\square$

$\underline{\mathbf{K}}$

1. I prefer to do things with others rather than on my own

2. I prefet to do things the same way over and over again

3. I tend to notice details thas others do not

4. I frequendly find that I don't know how to keep a conversation going

5. I like to collect information about categories $\square$ of things (e.g. types of car, types of bird, types of train, types of plant, etc.) 
L.

L1. I am on a diet because of the following illness:

Yes

No

a) Diabetes type I

b) Diabetes type II

c) Gluten intolerance

d) Lactose intolerance

e) Other food intolerance

f) Othor, what:

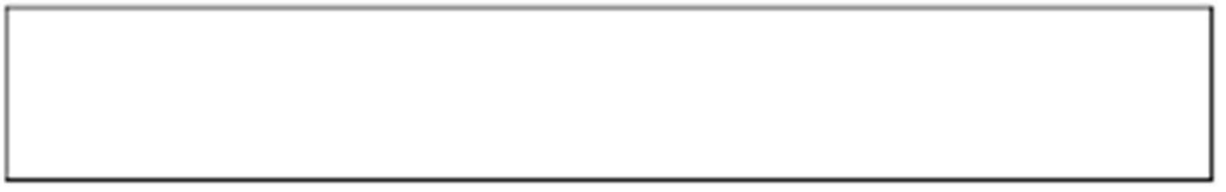

L.2. I am on a diet because I am:

Yes

No
a) Overweight $\square$
b) Underaxight $\square$

L.3. I avoid eating

Yes

No

a) Dairy products

$\square \quad \square$

b) Beef and pork (e.g. steaks, hamburgers or pork chops)

c) Poultry (e.g. chicken)

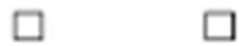

d) Fish and safood

$\square$

e) Vegetables

f) Fruit

8) Other, what:

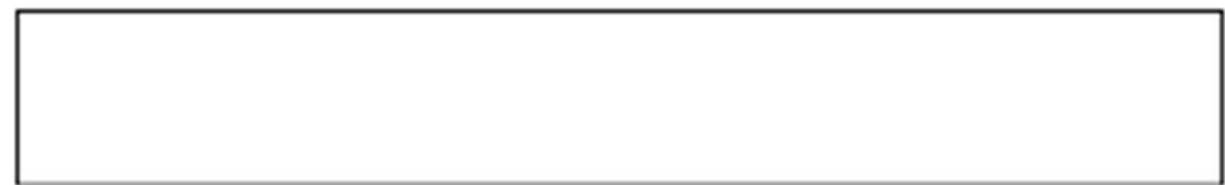

M

M1. I have received any of the following diagnoses

Yes

No
a) $\mathrm{ADHD}$
b) Asperger's sybdrome
c) Autisn'autistic syndrome 
d) Autistic like coedition/ atypical sutism

e) Touretle's syndroms

f) Obsessive compulsive disorder (OCD)

$\square \quad \square$

8) Anorexia nervosa

$\square \quad \square$

b) Bulimia servosa

i) Othet eating disordet e.g. binge eating disorder

j) Depression

k) Other psychiatric disotder, wha:

1) Hyperthyroidism

m) Diabetes type I

n) Diabctes Iype II

o) Gluten intokrance

p) Lactose intolerance

q) Other food imtolerance, what:

r) Bowel disease, ahat:

$\square \quad \square$

\section{:}

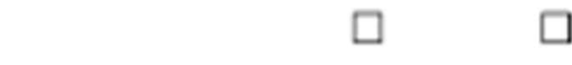

s) Bowel disease, abat:

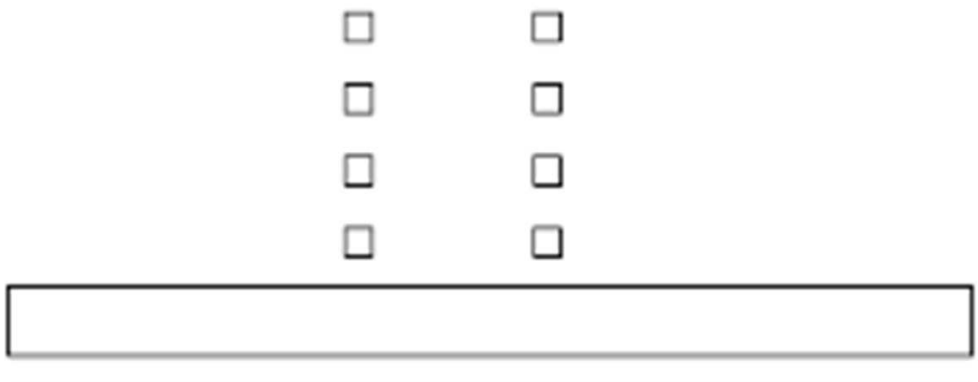

M2. I am treated with any of the following medications

Yes

No

a) Growth hormose

b) "Precocious puberty prevention" (e.g.

Dexapeplyl, Suptefakt, Procten)

c) "Antidepressants" (c.g. Fluoxetin,

Prozac, Sertralin, Zolon, Citalopram,

Cipramil)

d) "ADHD-mxidication" (e, \&. Coocerta, Ritalin or Strattera)

e) Neuroleptics (e g. Risperidon, Risperdal, Olanzapin, Zyprexa, Scroquel, Abilify)

f) Other, what:
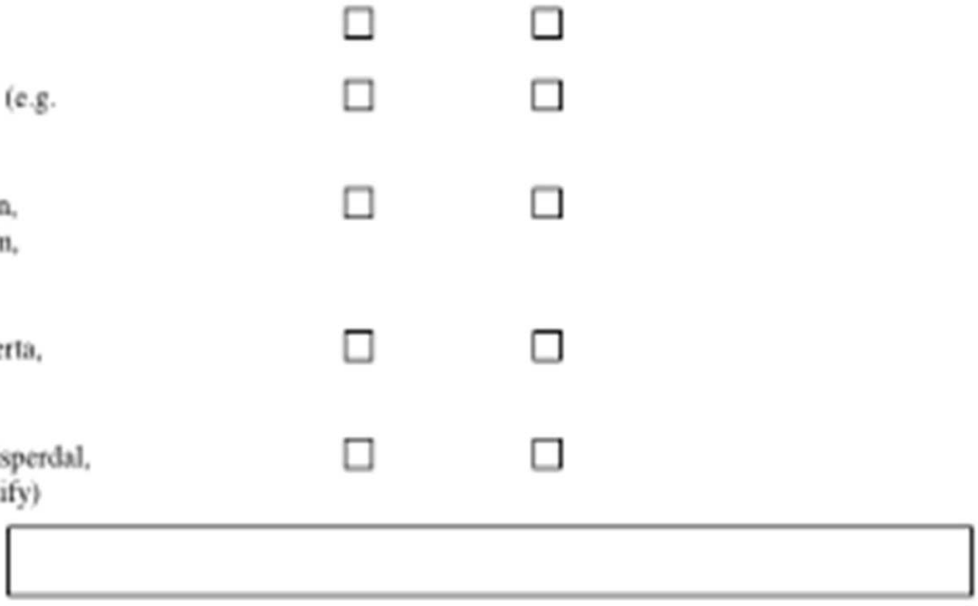